\title{
¿Patrimonio incompatible? Las cuevas de Valdepeñas (Ciudad Real)
}

\section{Domingo Fernández Maroto ${ }^{a}$, Ana María Medina Pérez y Tonka Ivanova Angelovac}

${ }^{a}$ UNED. Centro Asociado de Ciudad Real, C/ Mediodía, 17, 13300, Valdepeñas. dfernandez@valdepenas.uned.es, ${ }^{b} U N E D . C e n t r o$ Asociado de Ciudad Real, C/ Ntra. Señora de los llanos, 31, 13300, Valdepeñas. antropologa10@gmail.com y ${ }^{\mathrm{c} U N E D . ~ C e n t r o ~}$ Asociado de Ciudad Real, C/ Avenida Primero de julio, 13, 2º L, 13300, Valdepeñas. tonka.mail@gmail.com

\begin{abstract}
Resumen
Las cuevas de Valdepeñas son unos espacios arquitectónicos subterráneos realizados por la mano del hombre que, durante siglos, han cumplido una función fundamental: almacenar y conservar en el interior de las tinajas que contenían, el afamado vino de Valdepeñas. Sin embargo, en pleno siglo XXI, la mayoría de las cuevas permanecen abandonadas o, en el peor de los casos, han sucumbido ante el avance de nuevas construcciones que, sin tener en cuenta su valor patrimonial y sin unas medidas de protección adecuadas por parte de las administraciones implicadas, han provocado su paulatina desaparición. Hoy en día, algo parece estar cambiando en la mentalidad de la gente y en la aplicación de unas normativas que pueden ayudar a salvaguardar y poner en valor estas construcciones subterráneas tradicionales, que están empezando a ser valoradas como un recurso turístico más de esta población manchega.
\end{abstract}

Palabras clave: cuevas, conservación del patrimonio, Valdepeñas, vino, construcciones subterráneas, bodegas, arquitectura tradicional.

\begin{abstract}
Valdepeñas caves are underneath architectural spaces man-made that have achieved a main purpose for centuries: collect and preserve inside of jars the well-known wine from Valdepeñas. However, in the 21st century, most of the caves remain abandoned and even worse, they have succumbed facing the progress of new buildings without caring about their valuable heritage and without any proper protection measures, that should be taken by the authorities involved, this situation has provoked their gradual disappearance. Nowadays, something seems to be changing in people's mind and in some laws' application that can help in protecting and highlighting the importance of these traditional underground constructions that have just started to be valued such as another touristic resource from people of La Mancha.
\end{abstract}

Keywords: caves, heritage conservation, Valdepeñas, wine, underground buildings, winery, traditional architecture. 


\section{Introducción}

"Hoy daremos noticia de la portentosa cueva que hay en esta casa, objeto digno de la atención de los viajantes, como una de las siete maravillas de la Mancha y aún de la Europa" (Viera, 1774-1886, p. 124). Con esta expresividad exponía Viera Clavijo, un ilustrado que acompañaba al hijo del Marqués de Santa Cruz en su visita a Valdepeñas en 1774, la admiración que le habían causado las cuevas de Valdepeñas.

No es de extrañar que, en pleno siglo XVIII, causaran asombro al visitante estas galerías subterráneas repletas de tinajas de barro que contenían el afamado vino "Valdepeñas", puesto que hoy en día, aún siguen siendo lugares que impresionan; porque las cuevas de Valdepeñas son, junto con sus bodegas, el exponente esencial de una forma de vida y de una economía basada, durante siglos, en la cultura del vino; de hecho, podemos considerar que cuevas y bodegas forman la idiosincrasia de esta ciudad manchega, donde no se entendería su historia sin relacionarla con el vino, sus bodegas y sus cuevas.

Valdepeñas se localiza en la parte suroriental de la provincia de Ciudad Real, en un valle, dominando la entrada hacia la Meseta y Andalucía. El terreno calizo, la escasez de lluvias y las diferencias térmicas entre estaciones, influyen decisivamente en su desarrollo económico, basado durante siglos, en la viticultura. La vid, el cereal y el olivo, cultivos que conforman la trilogía mediterránea, son la base de su economía agrícola, caracterizando de manera singular este paisaje manchego.

Los antecedentes históricos de la viticultura en esta comarca los encontramos ya en época protohistórica, en el yacimiento íbero del Cerro de las Cabezas, donde se han identificado, en contextos arqueológicos del siglo III a.C., semillas de vitis vinífira o vid cultivada, así como herramientas utilizadas en las tareas agrícolas de la recogida de uva, tinajas y otros recipientes destinados al servicio de mesa, relacionados con la producción y consumo de vino (Vélez et al., 2013, pp. 144-145). Así mismo, hay datos arqueológicos que corroboran el cultivo de la vid en esta zona en época romana (Fernández et al., 2015, p. 2), y en épocas posteriores, en las que el incremento de la producción de vino está perfectamente documentado (Madrid, 1984, pp. 16-17; López-Salazar, 1994, p. 36; Peris, 2007, p. 17); algunas fuentes refieren que Valdepeñas llegó a tener en ciertos momentos “...casi quinientas cuevas destinadas a la producción de vino familiar" (Peris, 2007, p. 20).

No obstante, será a partir de la segunda mitad del siglo XIX, cuando la destrucción de los viñedos franceses por la filoxera (Marín, 2008) provocó una fuerte demanda de vinos españoles. Estas circunstancias coincidieron también con un aumento de la demanda interna y, sobre todo, con el importante acontecimiento de la llegada del ferrocarril a Valdepeñas el 24 de mayo de 1861 (Marín, 2017, p. 43), que supuso la posibilidad de abastecer de vino a otras zonas del país a través de este medio de transporte, más rápido y económico. Todos estos escenarios favorables propiciaron un incremento sustancial de la producción de vino en Valdepeñas a lo largo del último tercio del siglo XIX y principios del siglo XX, por lo que se hizo patente la necesidad de construir nuevas bodegas y cuevas, algo que la burguesía terrateniente valdepeñera de la época llevó a cabo, a la vez que construyeron grandes casas solariegas donde alojarse, casas que configuraron un nuevo urbanismo en la ciudad, con creación de nuevos barrios y nuevos accesos, condicionando un paisaje urbano cambiante y un subsuelo totalmente horadado de cuevas.

Para poder elaborar y conservar las cada vez más abundantes producciones de vino, que se depositaban en grandes tinajas de barro, eran necesarias estas bodegas, pero, sobre todo, las cuevas, donde la temperatura y humedad suelen ser constantes y tener escasas oscilaciones, por lo que el vino se conserva en unas condiciones óptimas; es por ello que el incremento en la construcción de bodegas y cuevas se fue haciendo exponencial al aumento en la producción de vino en esta época.

Los avances tecnológicos, los cambios de hábitos de consumo y otros condicionantes, propiciaron a lo largo de las últimas décadas del siglo XX que las cuevas se fuesen abandonando y olvidando, llevando a su colapso y su deterioro inexorable en muchos de los casos. Sin embargo, la mano del hombre resulta más letal para las cuevas que su propio abandono. Nos estamos refiriendo a la incidencia negativa que el "desarrollismo" urbanístico ha tenido sobre Valdepeñas en estos últimos años, lo que ha llevado a que muchas de estas cuevas, ubicadas tanto en el subsuelo de viviendas particulares, como de cercados y bodegas de la localidad, hayan sido destruidas para favorecer la 
construcción de modernas edificaciones, con el consiguiente deterioro y desaparición de una buena parte de este patrimonio.

Con estos antecedentes, desde diversos foros se intenta minimizar el impacto negativo sobre las cuevas, por lo que, en esa línea, se ha creado un equipo multidisciplinar, encargado del estudio y catalogación de las cuevas de Valdepeñas ${ }^{1}$, que tiene como finalidad, entre otras, promover acciones que redunden en la protección y el mantenimiento de estos peculiares espacios, testigos mudos de una ciudad y de una época.

En este artículo analizamos las consecuencias de la ausencia, hasta momentos recientes, de normas urbanísticas aplicadas a la protección y puesta en valor de este patrimonio subterráneo, así como la incidencia y condicionantes de las cuevas en el desarrollo urbano de Valdepeñas y, sobre todo, se hace referencia explícita al impacto que está teniendo la puesta en valor de estos elementos patrimoniales como recursos turísticos que puede disfrutar la ciudadanía.

Durante el proceso de documentación se ha trabajado en archivos, la prensa antigua, se han llevado a cabo entrevistas personales y la consulta de una amplia bibliografía que, junto con trabajo de campo que se está realizando en el que se visitan y se documentan in situ las cuevas y otros elementos patrimoniales, están proporcionando una extensa información que nos permite realizar un análisis en profundidad de las cuestiones propuestas.

\section{Orígenes, singularidad y significado de las cuevas de Valdepeñas}

Como hemos comentado, el vino se documenta en Valdepeñas ya en épocas protohistóricas, existiendo también algunas cuevas en el entorno de Valdepeñas próximas a algunos cauces fluviales, con cronologías semejantes, pero que, de momento, no muestran evidencias razonadas que justifiquen su utilización para el almacenamiento de vino, por lo que hemos de trasladarnos ya al siglo XVI; en el solar ocupado hoy por la Plaza de la Constitución, se localizó en el transcurso de la construcción de esta plaza y de los edificios aledaños, una cueva que presentaba un estrecho pasillo central, con espacios laterales excavados donde se situaban las tinajas de reducido tamaño, de no más de un metro aproximado de altura (Molina et al., 2007, p. 261). Posiblemente, esta cueva, desaparecida en parte durante estas obras, presente una cronología de principios del siglo XVI, por su similitud con otras de su entorno, como sucede con la cercana población de Villanueva de los Infantes. Así mismo, de finales del siglo XVI están consideradas otras cuevas existentes en Valdepeñas, como la del Museo Municipal, recuperada y adaptada para visitas turísticas (Fig. 1 izda.).

Otra cueva representativa es la del Museo de la Fundación Gregorio Prieto (Fig. 1 dcha.), también en vías de restauración, que presenta una cronología algo posterior, del siglo XVII (Fernández et al., en prensa). A partir de esta época, la excavación de cuevas debió ser cada vez más considerable, como recogen algunas fuentes a las que hemos aludido anteriormente.

Todas estas cuevas son estructuras artificiales realizadas generalmente por los trabajadores agrícolas que, durante días y días de intenso trabajo, en momentos en que no podían llevar a cabo las tareas agrícolas, fueron horadando a base de pico la roca caliza del subsuelo de esta localidad manchega. Este tipo de construcciones subterráneas han evidenciado a lo largo de los siglos una economía de medios, buscando máxima rentabilidad del trabajo de la mano de obra. Es, por tanto, una arquitectura que no necesita de planos ni arquitectos, aunque es evidente que sí existía una planificación previa, mínima, basada en las necesidades del momento y en la mano de obra disponible.

Las cuevas suelen mostrar varias características esenciales:

a) No representan épocas, dado que muchas de ellas son modificadas y ampliadas a lo largo de los siglos, en el contexto de la misma utilidad, siendo por ello muy complicado establecer a veces su cronología que, en ocasiones, viene definida por las tinajas que pueblan las entrañas de estas naves subterráneas.

\footnotetext{
${ }^{1}$ Esta labor se está llevando a cabo por las tres personas firmantes de este trabajo, en el marco del Proyecto "Inventario y catalogación de las cuevas de Valdepeñas como elementos patrimoniales" 2018-2020, investigación financiada por el Ayuntamiento de Valdepeñas, a través de la Concejalía de Cultura y que cuenta con la colaboración del Centro Universitario Asociado a la UNED de Ciudad Real en Valdepeñas.
} 
b) No responden a estilos, aunque pueden seguir unas pautas básicas, por lo que podemos considerarlas como unas construcciones de tipo tradicional, incluso en opinión de algunos autores, como una especie de arquitectura subterránea vernácula (Tillería, 2010, p. 12).

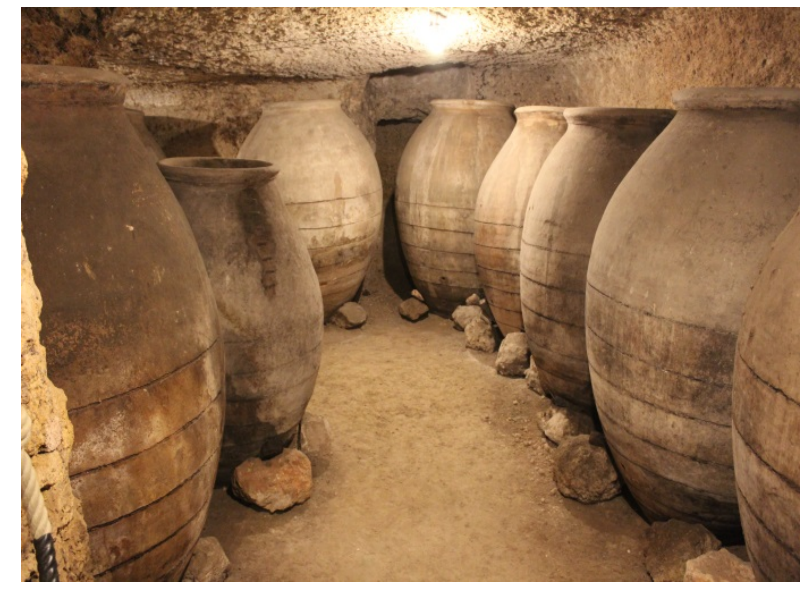

Fig. 1 Izda. Cueva del Museo Municipal de Valdepeñas, siglo XVI. Dcha. Cueva del Museo de la Fundación Gregorio Prieto, siglo XVII

c) Es una arquitectura adaptada, en cierto modo, al medio en el que se realiza, buscando en la excavación una profundidad estimada como recomendable para conseguir una higrometría y temperatura ideal que permita la buena conservación del vino, al mismo tiempo que la idoneidad de la excavación de la cueva se ve condicionada por la propia roca caliza -una roca sedimentaria, muy porosa- en la que se irán buscando aquellos estratos más fáciles de excavar, incluso aunque para ello haya que sobrepasar los límites de la edificación situada en superficie, prolongándose, a veces, fuera de estos.

d) Los materiales de construcción son escasos o nulos y las herramientas son también muy básicas: picos, palas, pequeños capachos de esparto o similar, pero, sobre todo, es fundamental la mano de obra de los "jornaleros" y el resto de personas que colaboran en este arriesgado y esforzado trabajo.

e) Aunque este tipo de arquitectura subterránea no es patrimonio exclusivo de la zona de Valdepeñas, documentándose en lugares muy dispares, sí podemos considerar que es una arquitectura anónima, en cierto modo, sin nombres propios que resaltar, porque es una tarea compartida, en la que la habilidad de los que trabajan en la cueva se basa en un bagaje de conocimientos que aplican a la obra, donde la preocupación por la arquitectura pasa a un segundo plano (Fernández y Picazo, 2016, p. 15). Es la experiencia consolidada y el dominio de estas técnicas las que, sin duda, fueron pasando de generación en generación, dando forma a las cuevas. De hecho, podemos considerar que estamos ante unas construcciones ecológicas, donde el impacto sobre el paisaje es nulo, sin apenas utilizar recursos de la naturaleza.

Con el paso del tiempo, estas construcciones subterráneas tradicionales pierden su esencia primigenia, sobre todo, con la modernización e industrialización de la industria del vino y el empleo de otros materiales, como el hormigón y el acero inoxidable, entre otros, utilizados en la construcción de depósitos que permiten llevar a cabo las mismas funciones que las cuevas y las tinajas, en cuanto a la conservación del vino se refiere. Por ello, las cuevas han ido entrando en un paulatino e irreversible declive, siendo abandonadas a su suerte en la mayoría de los casos.

Sin embargo, las cuevas son solo una parte de las construcciones que han dejado de ser utilizadas, junto a bodegas, así como cercados y casas solariegas. Todas estas edificaciones han sido durante los últimos años objeto de deseo de empresas constructoras y particulares los cuales, tras su adquisición, han optado en muchos casos, por su derribo para posteriormente, ocupar estos solares con nuevos y modernos edificios comerciales o de viviendas. Estas masivas construcciones han contribuido a la pérdida de un abundante patrimonio subterráneo que es el reflejo de la historia social y económica de esta localidad. 


\section{3. ¿Patrimonio incompatible?}

La UNESCO indica que "El patrimonio es nuestro legado del pasado, lo que vivimos hoy y lo que transmitimos a las generaciones futuras" ${ }^{\prime 2}$. Sin embargo, mantener ese patrimonio supone una tarea no exenta de problemas, de ahí que el título de este artículo incluye una interrogación que pone de manifiesto cuestiones como la vulnerabilidad de nuestro patrimonio subterráneo ante diversos factores. Las cuevas de Valdepeñas representan parte de las señas de identidad de este lugar, de sus gentes, de sus costumbres, pero es un patrimonio en peligro, si no se toma conciencia inmediata y tanto la sociedad como los responsables de las diversas administraciones implicadas no actúan aplicando las medidas oportunas. Solo así este patrimonio se puede consolidar como un recurso turístico, que supone también la posibilidad de rentabilidad social y económica, en donde en pleno siglo XXI, el patrimonio de nuestras ciudades juega un papel fundamental. Es por ello que este tipo de arquitectura subterránea debe llevarnos a interpretarla dentro de un "paisaje urbano subterráneo" que ha sido modelado por el ser humano a lo largo de siglos, aunque en estos momentos, y en la mayoría de los casos, ya no responden a la función inicial para las que se realizaron, si bien ello no implica que puedan pasar a tener otra función primordial en nuestra sociedad actual como elementos turísticos o con otros usos.

En el Censo que en 1975 realizó el Consejo Regulador de la Denominación de Origen Valdepeñas figuraban inscritas 414 bodegas, declarando solamente 37 cuevas, aunque este dato solo desvela las cuevas que en esos momentos aún estaban siendo utilizadas, porque otras muchas ya habían sido abandonadas con anterioridad. Sin embargo, sí es significativo como al ir cesando la actividad de muchas bodegas de tipo familiar a partir de estos años, también se fueron dejando abandonadas sus cuevas. Así, en septiembre de 2007 figuraban solo 32 bodegas y en la actualidad son 12 las inscritas, contando alguna más que no están registradas en esta entidad.

La posibilidad de recuperar y poner en valor estas construcciones subterráneas es lo que nos lleva a plantear el interrogante de la compatibilidad o no de este patrimonio en el momento actual, por lo que hemos de valorar y analizar tanto los factores positivos como negativos que inciden en la conservación y salvaguarda de las cuevas, bastantes de los cuales los hemos podido constatar en el transcurso de nuestra investigación y trabajo de campo.
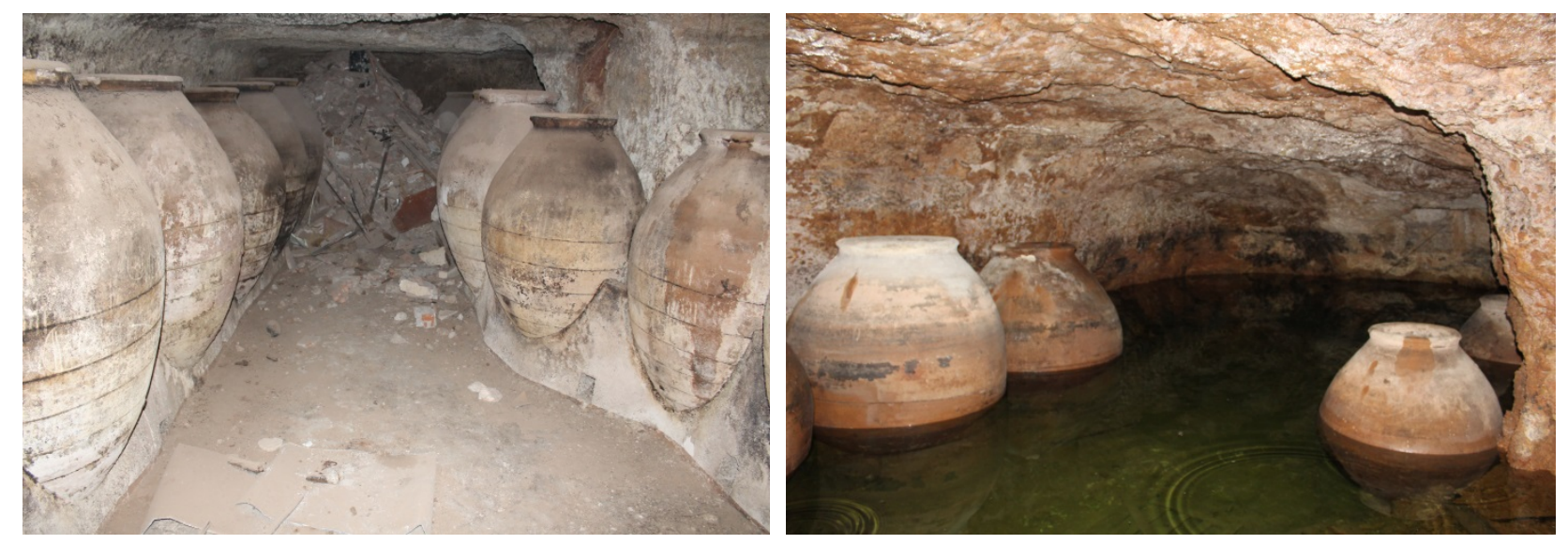

Fuente: Fotos Autores

Fig. 2 Cuevas que presentan serios deterioros debido a su abandono. En la cueva de la izquierda se puede observar cómo el respiradero ha sido utilizado para ir arrojando escombros y diversos enseres en el interior de la galería. En la imagen de la derecha se aprecia el agua inundando la cueva

\subsection{Factores negativos}

El abandono de las cuevas viene propiciado, como hemos dicho, por falta de utilidad práctica para las que fueron hechas, lo que implica la posibilidad de ocupar esos espacios físicos con nuevas construcciones, por lo que uno de los

\footnotetext{
${ }^{2}$ A este respecto, es fundamental el texto de la Convención sobre la Protección del Patrimonio Mundial Cultural y Natural (1972). Accesible en: http://whc.unesco.org/en/conventiontext/
} 
factores que más impacto ha tenido en la desaparición y destrucción de cuevas en Valdepeñas tiene que ver con las épocas en las que el incremento desmesurado y sin control de la construcción provoca la necesidad de buscar espacios para nuevas edificaciones, y estos se localizan en solares ocupados por bodegas y cercados que, en su subsuelo, poseen cuevas.
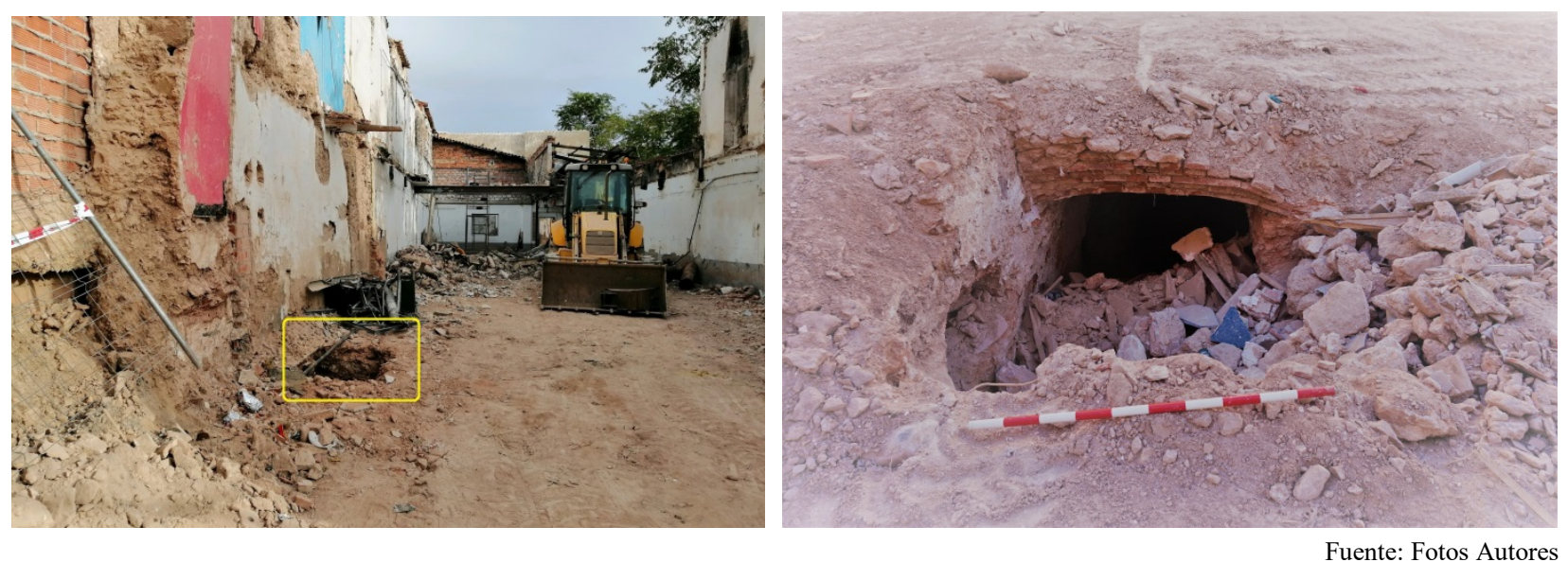

Fig. 3 Derribos de edificaciones que dejan al descubierto la entrada de cuevas que, en ocasiones, son destruidas o tapiadas

En los años 60 del pasado siglo se produjo en España la denominada por algunos autores, como fase de "aceleración y concentración urbana", repercutiendo negativamente en el patrimonio inmueble (Cebrián y Cebrián, 2000, p. 46). Efectivamente, en el caso de Valdepeñas, muchos inmuebles de estilo Modernista desaparecieron, al carecer por entonces de una legislación que los protegiera. Con aquellas destrucciones ya se vieron perjudicadas una parte de las cuevas. Décadas después, durante el boom de la construcción de principios de siglo XXI y la consiguiente especulación inmobiliaria que desembocó en la crisis global de 2008, se llevó a cabo en el casco urbano de la localidad la demolición de inmuebles, casas particulares, antiguas bodegas y cercados que contenían cuevas, siendo destruidas otra buena parte de ellas (Fig. 2).

Otro punto negativo a destacar es el relativo al deterioro paulatino que sufren las cuevas una vez son abandonadas y permanecen cerradas durante años. En este sentido, el estudio que venimos realizando nos ha permitido constatar que muchas de estas cuevas abandonadas llegan a colapsarse y están en completa ruina, debido a problemas de humedades por la falta de ventilación. Incluso, como se ha documentado en ocasiones, estos espacios subterráneos llegan a ser utilizados como vertederos o escombreras, donde se van depositando durante décadas, restos de obras, enseres antiguos de las casas, etc. A esto hay que añadir que algunas cuevas suelen inundarse periódicamente, debido a la eliminación de los pozos existentes en estas propiedades, que han provocado la subida del nivel freático de las aguas (Fig. 3).

\subsection{Factores positivos}

Afortunadamente, encontramos otras realidades positivas en cuanto a la recuperación de estas cuevas; recuperación que viene de la mano tanto de actuaciones privadas como públicas.

Por un lado, desde el punto de vista normativo, hasta la entrada en vigor del POM -Plan de Ordenación Municipal de Valdepeñas-, publicado en el BOP $\mathrm{n}^{\circ} 69$ de 8 de junio de 2011, prácticamente era inexistente cualquier procedimiento que impidiera la destrucción de estos espacios subterráneos, independientemente de su antigüedad. La Ley 4/2013 de Patrimonio Cultural de Castilla -La Mancha no recoge taxativamente la protección de las cuevas, como tampoco lo hace la Carta Arqueológica del municipio, realizada en 2005; sin embargo, unos años después, en 2011, el POM sí se refiere expresamente a la protección de las cuevas, pero dejando la puerta abierta a la posibilidad de su demolición: "Nivel de protección de cuevas y bodegas: Se establece una protección genérica sobre las cuevas y bodegas subterráneas existentes en el subsuelo de Valdepeñas. Sin embargo, podrá autorizarse su demolición si se aporta la documentación gráfica y fotográfica suficiente para dejar claramente reflejado su trazado, dimensiones y características...". 
Continúa el texto indicando que: "Toda la documentación de cuevas y bodegas deberá organizarse en un registro municipal de forma que, a pesar de la posible demolición de las mismas, quede documentada su existencia y características ya que se trata de un elemento íntimamente ligado a la historia de Valdepeñas".

Otro factor positivo resulta de la realización del inventario y catalogación de las cuevas, que puede y debe ser, un documento referente para posibles actuaciones, unido a la necesidad de difusión. Para ello, en el transcurso del trabajo que se viene realizando, se están realizando publicaciones, se imparten conferencias y otras acciones que permiten difundir y dar a conocer este patrimonio.
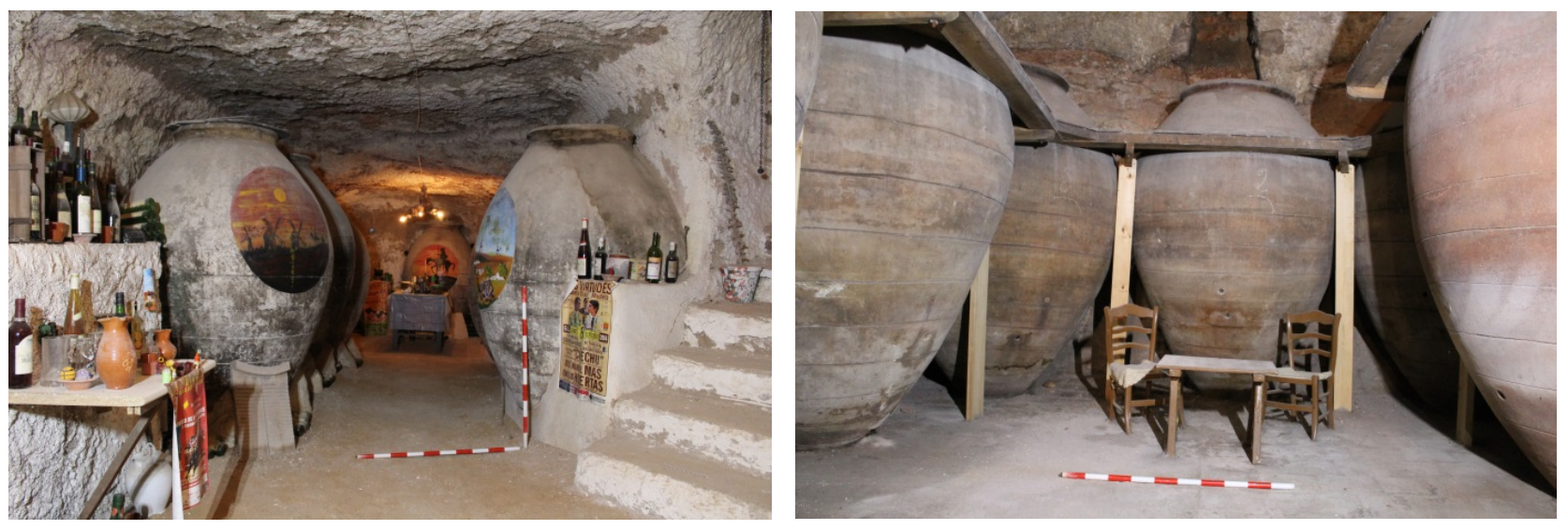

Fuente: Fotos Autores

Fig. 4 Cuevas habilitadas por los propietarios como espacios de ocio y disfrute

No menos importante es la iniciativa privada que, en el caso de algunos propietarios particulares de estos inmuebles, vienen manteniéndolos en perfectas condiciones de habitabilidad, habiéndoles dado un uso "doméstico", primando el disfrute de la cueva como un espacio de ocio familiar (Fig. 4).

Otras iniciativas privadas de empresarios han optado por reformar algunas de las cuevas adaptándolas para negocios relacionados con la hostería, restauración, bares y otros, como es el caso del establecimiento de vinos 11 Ánforas o el restaurante de la antigua Bodega Los Llanos, que funciona merced a una concesión a una empresa privada que se encarga de mantener abiertas y visitables las instalaciones de esta bodega rehabilitada por el Ayuntamiento de Valdepeñas.

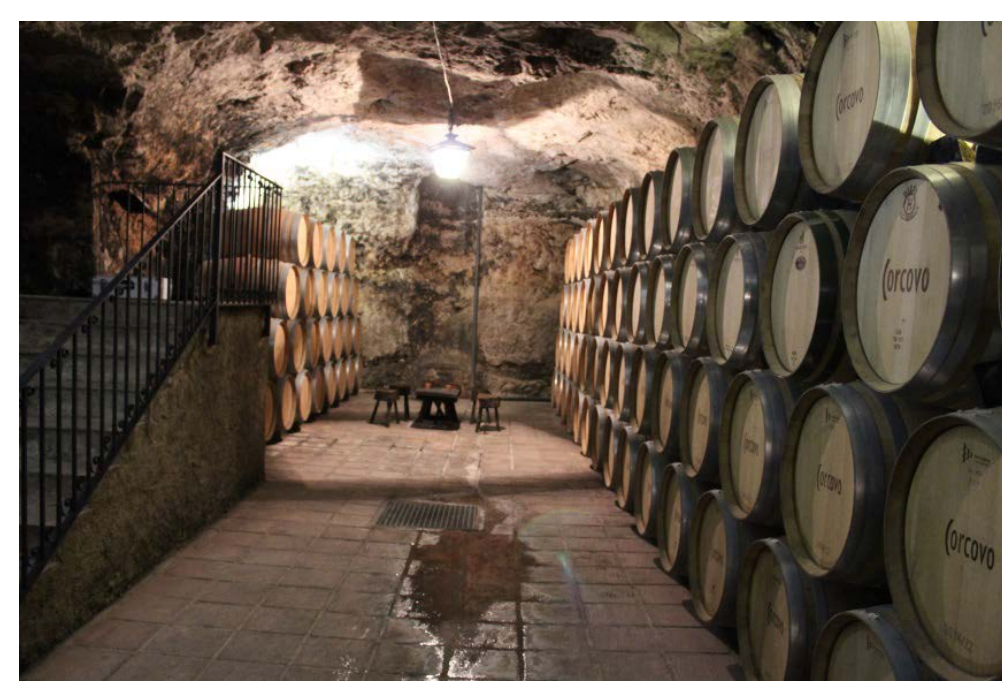

Fuente: Fotos Autores

Fig. 5 Cueva de la Bodega J. A. Megía e hijos, fundada en 1884. Hoy en día, las barricas de roble sustituyen a las antiguas tinajas 
También es significativo constatar cómo algunas bodegas se han decantado por seguir utilizando las cuevas para mantener determinados tipos de vinos, aunque sustituyendo las antiguas tinajas por barricas de madera de roble, caso de Bodegas J. A. Megía e hijos (Fig. 5), Bodegas Navarro López, La Bodega de las Estrellas, entre otras.

A todos estos casos hay que añadir las intervenciones que se vienen ejecutando por iniciativa pública, por parte del Ayuntamiento de Valdepeñas, tanto en la recuperación como en la posterior musealización y puesta en valor de varias cuevas de las más relevantes. Ello posibilita el disfrute de este patrimonio por parte de la ciudadanía, como sucede con la cueva del Museo Municipal de Valdepeñas, que presenta una cronología del siglo XVI, rehabilitada y restaurada para hacerla visitable; la cueva del Museo del Vino, que ocupa las instalaciones de la antigua bodega de Leocadio Morales, fechada en 1901; la cueva de la mencionada bodega de los Llanos, datada en 1875, que fue ampliándose con diversas galerías (Fig. 6); la cueva de la Escuela de Música, en proceso de rehabilitación en estos momentos. Destaca también la labor de recuperación que se está realizando en la cueva del Museo de la Fundación Gregorio Prieto, datada en el siglo XVII.
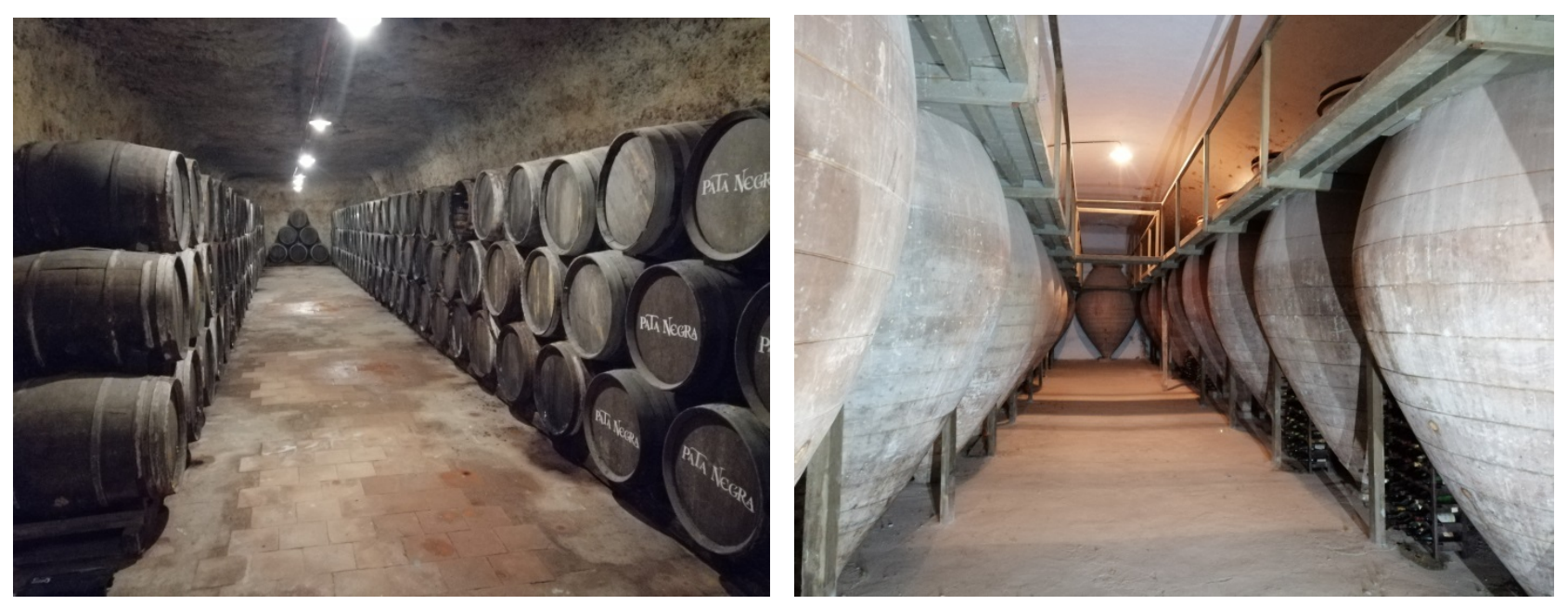

Fuente: Fotos Autores

Fig. 6 A la izda., una de las galerías de la cueva de Bodega los Llanos. A la dcha., la cueva del Museo del Vino de Valdepeñas; ambas rehabilitadas por el Ayuntamiento de Valdepeñas para hacerlas visitables

\section{Conclusiones}

Las cuevas de Valdepeñas son el testigo mudo de una época de esplendor. A lo largo de esta exposición, hemos querido poner de manifiesto los riesgos y peligros que acechan a un patrimonio tan vulnerable como son las cuevas de la Ciudad del Vino y, por extensión las cuevas de nuestros pueblos que, como hemos comprobado, presentan unas escasas medidas de protección, evidenciando que este potencial patrimonio aún dista mucho de ser protegido totalmente. Para ello sería preciso, por un lado, una mayor concienciación de las administraciones públicas; pero sin duda, es la propia ciudadanía la que más debe incidir en su protección y salvaguarda, dado que este patrimonio representa la seña de identidad cultural de un pueblo.

En este sentido, sin duda, las actuaciones de empresas privadas también pueden contribuir a su conservación; como hemos visto, empresas privadas dedicadas a la hostelería e incluso bodegas familiares, van recuperando estos espacios subterráneos empleándolos como un recurso turístico más, o vuelven a utilizarlos rellenando nuevamente de vino las entrañas de estas cuevas, ya sea en barricas de madera o en antiguas tinajas en las que se empiezan a elaborar vinos ecológicos.

Por otra parte, es fundamental la labor que lleva a cabo la administración local en Valdepeñas, donde el Ayuntamiento de esta localidad ha recuperado ya varias de las cuevas más emblemáticas y que pueden ser visitadas. 
Todas estas intervenciones posibilitan ampliar los recursos turísticos de Valdepeñas, lo que nos permite considerar que este patrimonio subterráneo puede rentabilizarse ante la demanda, cada vez mayor, de un turismo de interior en constante auge.

Es por ello que, el inventario y catalogación en el que estamos trabajando, se nos muestra como una herramienta fundamental y muy necesaria, porque nos facilitará en un futuro a medio plazo, la posibilidad de contar con unos datos que nos van a proporcionar una visión de conjunto de estas estructuras a lo largo de varios siglos, y un conocimiento más exhaustivo, algo que permitirá, además, acercarnos a la historia económica y social de Valdepeñas.

Las situaciones que hemos expuesto nos llevan a la conclusión que, efectivamente, las cuevas de Valdepeñas son un patrimonio sostenible, lo que permite que su uso y disfrute sea totalmente viable y compatible en pleno siglo XXI.

\section{Referencias}

Ayuntamiento de Valdepeñas. (2011). Plan de Ordenación Municipal de Valdepeñas. Normas urbanísticas (POM). En BOP, 69.

Cebrián, F., y Cebrián, A. (2000). Los desequilibrios en la estructura urbana de Castilla -La Mancha. Papeles de Geografía 32, 4559. Recuperado de: https://revistas.um.es/geografia/article/view/47311/45331.

Fernández Maroto, D., y Picazo Carrión, Ll. (2016). Arquitectura de piedra seca de la comarca de Valdepeñas. Una arqueología del paisaje rural manchego. En F. Alía Miranda, J. Anaya Flores, L. Mansilla Plaza, y J. Sánchez Lillo (Coords.), II Congreso Nacional Ciudad Real y su Provincia (pp. 13-41). Ciudad Real: Diputación Provincial de Ciudad Real.

Fernández Maroto, D., Ivanova Angelova, T., y Medina Pérez, A. M. (En prensa). Patrimonio subterráneo: el silencio roto de las cuevas de Valdepeñas. En Legatum 2.0. II Congreso Internacional de Musealización y Puesta en Valor del Patrimonio Cultural. Daimiel.

Fernández Maroto, D., Vélez Rivas, J., Torres González, T., y Pérez Avilés, J.J. (8 de noviembre de 2015). Primeros indicios de la existencia de torcularia romanos, para la elaboración de vino y aceite, en el “Área de Valdepeñas”. En Diario Lanza, 2-3.

Ley 4/2013, de 16 de mayo, de Patrimonio Cultural de Castilla-La Mancha.

López Salazar Pérez, J. (1994). Valdepeñas 1752. Según las respuestas generales del Catastro de Ensenada. Madrid: Tabapress.

Madrid Medina, Á. (1984). Valdepeñas. Ciudad Real: Instituto de Estudios Manchegos.

Marín Arroyo, D. (2008). Crisis filoxérica y de exportaciones: ¿Realidad o mito?. Cuaderno de Estudios Manchegos, 33, 156-183.

Marín Arroyo, D. (2017). El ferrocarril en la provincia de Ciudad Real. Estaciones, líneas y proyectos. Puertollano: Ediciones C\&G, Puertollano.

Molina Chamizo, P., Moraleda Sierra, J., Álvarez García, J., Sánchez Sánchez, J. L., Ruíz Sánchez, A., y Benítez de Lugo Enrich, L. (2007). Arqueología y desarrollo urbano en Valdepeñas (Ciudad Real). Bodegas subterráneas y casas señoriales ante el proyecto de ampliación de la Plaza de España. En M. Zarzalejos, M. A. García y L. Benítez de Lugo (Eds.), I Congreso de Patrimonio Histórico de Castilla- La Mancha. La Gestión del Patrimonio Histórico Regional (pp. 257-285). Tomo II, Valdepeñas: UNED Ciudad Real y Diputación de Ciudad. Real.

Peris Sánchez, D. (2007). Bodegas de Valdepeñas: Arquitectura, ciudad y paisaje. En VV. AA, $2^{\circ}$ Ciclo de conferencias Valdepeñas y su historia (pp. 13-97). Valdepeñas: Ayuntamiento de Valdepeñas.

Tillería González, J. (2010). La arquitectura sin arquitectos, algunas reflexiones sobre arquitectura vernácula. Revista AUS, 8, 12-15.

Vélez Rivas, J., Pérez Avilés, J. J., y Torres González, T. (2013). Cerro de las Cabezas: almacenes y graneros. Orisos, Revista de investigación y divulgación cultural, 2, 103-150.

Viera Clavijo, J. (1774-1886). Viaje a la Mancha en 1774. Publicado por Cesáreo Fernández Duro. Boletín de la Real Sociedad Geográfica, 21, 114-141. Recuperado de:

http://realsociedadgeografica.com/boletines/Tomo\%20XXI\%20A\%F10\%20XI\%20N\%FAmero\%201\%20-\%201886\%20Julio.pdf 